\title{
Promoting sense of security in old-age care
}

\author{
Martina Boström ${ }^{1}$, Marie Ernsth Bravell ${ }^{1}$, Dan Lundgren ${ }^{2}$, Anita Björklund ${ }^{3}$ \\ ${ }^{1}$ Institute of Gerontology, School of Health Sciences, Jönköping University, Jönköping, Sweden; \\ *Corresponding Author: bosm@,hhj.hj.se \\ ${ }^{2}$ Department of Organizational Development, Division of Social Services, The Research School Health and Welfare, School of \\ Health Sciences, Jönköping University, Jönköping, Sweden \\ ${ }^{3}$ Department of Rehabilitation, School of Health Sciences, Jönköping University, Jönköping, Sweden
}

Received 15 April 2013; revised 15 May 2013; accepted 3 June 2013

Copyright (C) 2013 Martina Boström et al. This is an open access article distributed under the Creative Commons Attribution License, which permits unrestricted use, distribution, and reproduction in any medium, provided the original work is properly cited.

\begin{abstract}
Purpose: The concept of security is related to the experience of health but has ever so often been argued from a risk perspective rather than from a promotional perspective. The experience of older persons' sense of security in private homes and in nursing homes seems to be missing when it comes to promote aging well throughout the life span. This study aimed to describe and analyze factors related to the sense of security of older persons receiving care in nursing homes in Sweden. Design and Methods: The study was based on a questionnaire from a total of 495 persons aged $\geq 65$ in private homes $(n=350)$ or nursing homes $(n=$ 145) in Sweden. Results: Secure relationships, sense of control, and perceived health were significantly related to the subjects' sense of security. No significant relationships were found between sense of security and having a personal emergency response alarm. Implications: Experience of sense of security from the older person perspective differs depending on the context. To promote the sense of security within the care of older persons, methods on how to establish secure relations as well as the sense of control and knowledge need to be further tested, developed and analyzed together with older persons.
\end{abstract}

Keywords: Sense of Security; Nursing Homes; Regression Analysis; Health Promotion

\section{INTRODUCTION}

An increased interest in the concept of security has risen over the past decade since the sense of security has been identified as being related to healthy aging, quality of life in later years, and aging well [1-5]. In many countries around the world such as in Sweden, policy documents encompass strategies offering the elderly the possibility to "age in place" and "to grow old in security while maintaining their independence" [6]. The strategy "to age in place" usually refers to being able to stay in one's own home as long as the old person wishes to do so and feels confident and secure [7]. Research has, however, indicated that municipalities are not able to offer sufficient safety and security to older persons who want to age in place [8], indicating that promoting a sense of security and independence is still a public policy challenge in Sweden and other developed countries for supporting older persons aging in place [9]. Research regarding the older person's experiences of sense of security in private homes and in nursing homes seems to be missing.

Despite the importance of health care staff's understanding of the safety implications for persons with certain diseases and symptoms to promote security [10], research has often described feelings related to insecurity rather than security. The concept of security has often been argued from a risk perspective, like the risk of falling or the fear of crime, which does not necessarily deepen the understanding of how to promote security for older persons in different contexts $[2,3]$. We believe that promoting a sense of security could broaden the understanding of what promotes security for older persons rather than deepen the knowledge of what factors hinder insecurity.

In Sweden, the National Board of Health and Welfare evaluates and sets policy to examine its impact on the everyday life of older persons in private homes and nursing homes. One way to measure the set strategies is accomplished by sending out a yearly survey to every resident who receives care in the municipality. Since it is the responsibility of the authorities to promote older persons' 
sense of security and independence, it is no surprise that the survey targets topics such as security, social care, and perceptions of received health care [11]. As noted, the survey is one of the most important bases for the forthcoming political decisions and priorities regarding, for example, how to make it possible for older persons to "age in place" and to "grow old in security". Previous studies regarding evaluations of the surveys that have been sent to every resident who receives care in the municipality have shown that the political intentions have not always been successful in practice regarding the care for older persons [12]. Since the evaluations are rarely done on a scientific basis, the quality of the surveys outcome might be insufficient and misleading for the future strategies that should be set by the National Board of Health and Welfare.

Having control over economic situations might reduce insecurity for older persons [13], whereas in a caring context relationships with personnel, relatives, and friends were found to be key issues for feeling secure [13]. The health care staff also needs to perceive a sense of security themselves so that trustworthy relationships with health care receivers can be obtained [14]. In conclusion, research regarding the older person's experiences of sense of security when they are dependent on health and social care in their daily life while, for instance, living in a private home or nursing home seems to be missing $[3,4,13]$. Therefore, there is a need for increased knowledge of what promotes security for older persons. The objective of this study was to describe and analyze factors that may relate to a sense of security for older persons receiving old-age care in everyday life. More specifically we wanted to:

- Describe the current sense of security based on respondents living in private homes and nursing homes;

- Investigate if there is a difference in sense of security between nursing home residents and residents that receive care and services in private homes;

- Explore factors related to the sense of security.

The theoretical starting point is the Model of Security suggested by Segesten [15] in 1984. Segesten [15] notes that security is a multidimensional concept that has to do with safety, confidence, and trust. However, security could be divided into two dimensions; first, as a feeling within the person, and secondly, related to interactions within the surrounding world [16]. The interaction within the surrounding world is conceptualized by Segesten [15] as the external security, and divided into secure relationships (relationships where he/she feels respected) and sense of control and knowledge (having knowledge about what is required to cope and manage situations). This is in line with factors for obtaining the sense of security according to 1) Gidden's [17] concept of sense of security, where one of the most important factors for achieving sense of security is a society characterized by face-to-face relationships; and 2) with the theoretical model of "perceived insecurity" according to Carro et al. [18]. According to Carro et al. (2010), "personal competence" with components such as gender, social support, age, and personal control may have an impact on the sense of insecurity and is consequently assumed to have an impact on security as well.

\section{DESIGN AND METHODS}

The analyses were based on secondary analyses of a questionnaire that was distributed to all persons aged $\geq$ 65 years who received old-age care in a municipality in the South of Sweden, including home help care services, meals on wheels, and/or security alarms in private homes $(\mathrm{PH})$, or care in nursing homes $(\mathrm{NH})$.

\subsection{Sample}

A total of 3018 individuals were invited to complete the survey; 1547 living in private homes and 1471 living in nursing homes. Seven hundred sixty (49\%) in the $\mathrm{PH}$ group responded and $802(54 \%)$ in the NH group responded, giving a total response rate of 52\% (1562 responders). The analyses for this study required the respondents' subjective evaluations. Therefore, this study only concerns those who answered the questions themselves, resulting in a sample size of 495 persons $(n=350$, $\mathrm{PH} ; \mathrm{n}=145 \mathrm{NH}$ ).

\subsection{Measures/Questionnaire}

The questionnaire used for the analyses aimed to evaluate older persons' perceptions of the old-age care and the services they received. All questions were constructed by the municipal development unit of older age care, formed and produced with guidelines from the National Board of Health and Welfare [19,20]. In total, 35 questions regarding private homes and 36 questions regarding nursing homes were included in the survey. This study analyzed ten questions related to security since these questions were identical between the surveys provided to the $\mathrm{PH}$ and $\mathrm{NH}$ groups, and therefore comparative. The questions analyzed in this study were related to respect, participation, safety, information and confidence. Besides from the questions that were analyzed for this study, the questionnaire also targets psychosocial experiences like food assistance (size of the portions, taste of the food and time related questions like do you get your food basket at the promised time) social contacts (need of contact with other persons than the staff) and overall impressions of the care (expectations of the received care, how close or far from perfect assistance the 
received care is and active choice regarding care providers). Responses to six questions were based on a Likert scale with a range from 1 to 6 where the higher number indicated more positive answers. Four of the questions had $1=$ yes or $0=$ no response selections (see Table 1 ).

\subsection{Analyses}

As an initial step, we examined the distribution of scores on all measures, including skewedness and kurtosis. The next step included non-parametric, descriptive analyses, such as chi-square and t-tests in order to identify differences between those living in private homes and those living in nursing homes. The power and effect size for the t-test were tested with Cohens, D. and found to be $>0.2$ in all analyses.

For the following questions t-tests were performed: 1) to what extent do you feel that your individual needs are taken into consideration? 2) to what extent do you feel that the social care staff show you respect; 3) to what extent do feel that the social care staff show an interest in you and your situation; 4) to what extent do you feel that you are taking part in decisions made regarding your situation; 5) to what extent do you feel that the social care staff you interact with have sufficient knowledge of their work? 6) to what extent do you feel confidence in your social care staff? Chi-square tests were performed for the following questions; 7) have you, together with the health care staff, made an implementation plan for the assistance you receive; 8) have you received a designated contact person; 9) do you know where to turn if you have complains concerning the old-age care; 10) do you have knowledge about the municipal service guarantees.

In order to optimally analyze relationships to "sense of security", the number of independent variables needed to be reduced. Therefore, a factor analysis (principal component) with Varimax rotation was performed including the ten questions from the questionnaire. The factor analysis resulted in two components, and matched the model of external security derived from Segesten (1984).

The two components resulting from factor analysis

Table 1. Characteristics of the questionnaire respondents and responses to specific questions.

\begin{tabular}{|c|c|c|c|c|c|c|c|c|}
\hline & \multicolumn{2}{|c|}{$\begin{array}{l}\text { Private homes } \\
\quad(n=350)\end{array}$} & \multicolumn{2}{|c|}{$\begin{array}{l}\text { Nursing homes } \\
\qquad(n=145)\end{array}$} & \multicolumn{2}{|c|}{ Total $(n=495)$} & & \\
\hline Male & \multicolumn{2}{|c|}{31} & \multicolumn{2}{|c|}{27} & \multicolumn{2}{|c|}{30} & & \\
\hline Female & \multicolumn{2}{|c|}{69} & \multicolumn{2}{|c|}{73} & \multicolumn{2}{|c|}{70} & & \\
\hline Married & \multicolumn{2}{|c|}{14} & \multicolumn{2}{|c|}{16} & \multicolumn{2}{|c|}{15} & & \\
\hline Widowed & \multicolumn{2}{|c|}{62} & \multicolumn{2}{|c|}{64} & \multicolumn{2}{|c|}{63} & & \\
\hline Divorced & \multicolumn{2}{|c|}{13} & \multicolumn{2}{|c|}{8} & \multicolumn{2}{|c|}{11} & & \\
\hline \multirow[t]{2}{*}{ Unmarried } & \multicolumn{2}{|c|}{11} & \multicolumn{2}{|c|}{12} & \multicolumn{2}{|c|}{11} & \multirow{3}{*}{$\mathbf{t}$} & \multirow{3}{*}{$p$} \\
\hline & $\mathrm{M}$ & (SD) & $\mathrm{M}$ & (SD) & $\mathrm{M}$ & (SD) & & \\
\hline Mean age & 82.53 & $(6.51)$ & 84.32 & $(7.41)$ & 83.05 & $(6.83)$ & & \\
\hline $\begin{array}{l}\text { To what extent do you feel that your individual needs are taken } \\
\text { into consideration? }\end{array}$ & 4.98 & $(1.10)$ & 5.06 & $(1.04)$ & 5.00 & $(1.08)$ & 0.686 & 0.493 \\
\hline $\begin{array}{l}\text { To what extent do you feel that the social services staff show } \\
\text { you respect? }\end{array}$ & 5.20 & $(0.95)$ & 5.26 & $(0.97)$ & 5.22 & $(0.96)$ & 0.607 & 0.544 \\
\hline $\begin{array}{l}\text { To what extent do you feel that the social service staff show an } \\
\text { interest in you and your situation? }\end{array}$ & 4.95 & $(1.05)$ & 5.09 & $(1.02)$ & 4.99 & $(1.05)$ & 1.388 & 0.166 \\
\hline $\begin{array}{l}\text { To what extent do you feel that you are taking part in decisions } \\
\text { made regarding your situation? }\end{array}$ & 4.62 & $(1.39)$ & 4.63 & $(1.53)$ & 4.62 & $(1.43)$ & 0.074 & 0.941 \\
\hline $\begin{array}{l}\text { To what extent do you feel that the social care staff you interact } \\
\text { with have sufficient knowledge of their work? }\end{array}$ & 4.79 & $(1.12)$ & 4.96 & $(1.19)$ & 4.84 & $(1.14)$ & 1.416 & 0.157 \\
\hline To what extent do you feel confidence in your social care staff? & 5.06 & $(1.09)$ & 5.23 & $(1.00)$ & 5.11 & $(1.06)$ & 1.653 & 0.099 \\
\hline Do you feel secure in your everyday life? & 5.11 & $(1.08)$ & 5.38 & $(0.95)$ & 5.19 & $(1.05)$ & 2.676 & $0.008^{* *}$ \\
\hline \multirow[t]{2}{*}{ How would you describe your health status? } & 4.02 & $(1.16)$ & 4.30 & $(1.22)$ & 4.10 & $(1.18)$ & 2.440 & $0.015^{*}$ \\
\hline & & & & & & & $\chi^{2}$ & $p$ \\
\hline Have implementation plan ${ }^{1}$ & 202 & $(61 \%)$ & 71 & $(54 \%)$ & 273 & $(59 \%)$ & 1.490 & 0.222 \\
\hline Have appointed liaison ${ }^{1}$ & 225 & $(66 \%)$ & 119 & $(91 \%)$ & 344 & $(73 \%)$ & 21.753 & $0.000^{*}$ \\
\hline Knows how to complain if dissatisfied ${ }^{1}$ & 188 & $(59 \%)$ & 79 & $(60 \%)$ & 267 & $(60 \%)$ & 0.054 & 0.816 \\
\hline Knows about service Guarantees ${ }^{1}$ & 71 & $(22 \%)$ & 27 & $(21 \%)$ & 98 & $(22 \%)$ & 0.060 & 0.806 \\
\hline
\end{tabular}

${ }^{*} p<0.05,{ }^{* *} p<0.01 ;{ }^{1}$ yes; Abbreviations: $\mathrm{M}=$ mean; $\mathrm{SD}=$ standard deviation. 
were named "secure relations" and "sense of control and knowledge", and were retrieved from the theory of Segesten [15]. The component "secure relations" included six questions $(1-6)$ related to perceived experience of the caregiver; namely, to what extent do you feel that your individual needs are taken into consideration; to what extent do you feel that the social care staff show you respect; to what extent do you feel that the social care staff show an interest in you and your situation; to what extent do you feel that you are taking part in the decisions made regarding your situation; to what extent do you feel confidence in your social care staff; to what extent do you feel that the social care staff you interact with have sufficient knowledge of their work (alpha = 0.91). The second component, "sense of control and knowledge" included four questions (7 - 10) and involved having control and knowledge of the current situation; namely, have you, together with the health care staff, made an implementation plan for the assistance you receive; have you received a designated contact person; do you know where to turn if you want to complain; do you have knowledge of the municipal service guarantees. Of note, the model of sense of security derived from Segesten (1984) comprises additional categories that were not addressed in the survey, and therefore were not measured in this study.

Finally, we performed OLS multiple regressions for the dependent variable in order to understand the relationship between sense of security and "secure relations", "sense of control and knowledge", sociodemographic factors, and perceived health. In the OLS, multiple regressions using the sample living in private homes, the variable "do you have a personal emergency response alarm" was added.

\subsection{Dependent Variables}

For the regression analyses, "sense of security" was used as an outcome variable and was measured by the question, "Do you feel secure in your everyday life/ (daily living)?"

\subsection{Independent Variables}

In our study, we wanted to investigate sense of security in two different samples; older persons living in private homes with old-age care, and older persons living in nursing homes. In order to identify factors related to perceived sense of security, we included sociodemographics, relationships, knowledge and control, and health status in three regression analyses; one including the total sample $(n=495)$, a second using the sample of older persons living in private homes $(n=350)$, and a third using the sample of older persons living in nursing homes $(n=145)$. For the third regression analyses, use of personal emergency response alarms (PERS) with responses of yes (1) or no (0) was added as an independent variable.

The sociodemographic variables included were age, gender, and marital status. Increasing age has been reported to be related to decreased sense of security $[3,4,21]$. Gender, as well as marital status, has also been reported to be related to sense of security. Men feel more secure than women. Living alone without a partner in older age has also been shown to decrease feelings of security [18]. Relationships were shown to be important for promoting sense of safety in older age, but research regarding social support from a home help service, for example, was found to be less researched [4]. Perceived accessibility of support and know-how was more important for security feelings than, for example, environmental variables [18], which promote the use of sense of knowledge and control as an independent variable. Perceived health related to security has shown that the better the older person experiences their health status, the more secure they feel $[22,23]$. Finally, a qualitative study concerning PERS and older persons showed that the personal alarms induced feelings of insecurity in older persons rather than of security [24].

\section{RESULTS}

\subsection{Descriptive Results}

The descriptive analysis demonstrated that the sample drawn from the $\mathrm{PH}$ group was quite similar to the sample drawn from the NH group with regards to the sociodemographic variables. Marginally more men than women were living in $\mathrm{PH}$, and slightly more persons in $\mathrm{PH}$ also seemed to be divorced. Our data also demonstrate that the sense of security in older persons living in $\mathrm{PH}$ and NH was relatively high.

Furthermore, older persons living in $\mathrm{NH}$ seemed to experience increased security in their everyday life compared with older persons living in $\mathrm{PH}(t=2.676, p=$ $0.008)$. There were also significant differences in perceived health $(t=2.44, p=0.015)$; older persons living in $\mathrm{PH}$ perceived their health as better than persons living in $\mathrm{NH}$. Persons living in $\mathrm{PH}$ reported having a designated trustee less often than those living in $\mathrm{NH}$.

\subsection{Factors Related to Sense of Security}

The regression analysis demonstrated that there were no significant relationships between sociodemographic variables such as age, gender, or marital status and sense of security. Secure relations, sense of control, and perceived health demonstrated significant relationships with sense of security in both samples. There was no significant relationship between sense of security and having a personal emergency response alarm among the sample 
Table 2. Multiple regression analysis of sense of security in private homes $(\mathrm{PH})$, nursing homes $(\mathrm{NH})$, and total $(\mathrm{OH}+\mathrm{NH})$ group.

\begin{tabular}{|c|c|c|c|c|c|c|c|c|c|}
\hline \multirow{2}{*}{$\begin{array}{l}\text { Self-rated } \\
\text { Variables }\end{array}$} & \multicolumn{3}{|c|}{ Private Homes } & \multicolumn{3}{|c|}{ Nursing Homes } & \multicolumn{3}{|c|}{ Total } \\
\hline & $B$ & $\beta$ & CI for $B$ & $B$ & $\beta$ & CI for $B$ & $B$ & $\beta$ & CI for $B$ \\
\hline \multicolumn{10}{|c|}{ Model 1} \\
\hline Age & -0.003 & -0.019 & $-0.025-0.019$ & 0.024 & 0.178 & $-.005-0.052$ & 0.007 & 0.050 & $-0.010-0.025$ \\
\hline Gender & 0.038 & 0.017 & $-0.264-0.339$ & 0.136 & 0.065 & $-0.305-0.577$ & 0.081 & 0.037 & $-0.165-0.327$ \\
\hline Marital status & -0.072 & -0.057 & $-0.250-0.106$ & 0.172 & 0.144 & $-0.091-0.435$ & 0.001 & 0.001 & $-0.145-0.147$ \\
\hline \multicolumn{10}{|c|}{ Model 2} \\
\hline Age & -0.006 & -0.037 & $-0.022-0.010$ & 0.010 & 0.073 & $-0.008-0.028$ & 0.001 & 0.007 & $-0.011-0.013$ \\
\hline Gender & -0.034 & -0.016 & $-0.249-0.180$ & 0.131 & 0.063 & $-0.143-0.028$ & 0.022 & 0.010 & $-0.148-0.192$ \\
\hline Marital status & -0.097 & -0.077 & $-0.227-0.032$ & 0.099 & 0.083 & $-0.065-0.263$ & -0.041 & -0.032 & $-0.142-0.061$ \\
\hline Secure relations & $0.691^{* * *}$ & 0.661 & $0.588-0.793$ & $0.633^{* * *}$ & 0.623 & $0.486-0.780$ & $0.686^{* * *}$ & 0.659 & $0.602-0.769$ \\
\hline $\begin{array}{l}\text { Sense of control and } \\
\text { knowledge }\end{array}$ & $0.147^{* *}$ & 0.145 & $0.048-0.245$ & $0.255^{* *}$ & 0.228 & $0.108-0.402$ & $0.161^{* * *}$ & 0.156 & $0.081-0.241$ \\
\hline Perceived health & $0.133^{* *}$ & 0.138 & $0.036-0.230$ & $0.132^{*}$ & 0.172 & $0.021-0.243$ & $0.127^{* *}$ & 0.141 & $0.054-0.200$ \\
\hline \multicolumn{10}{|c|}{ Model 3} \\
\hline Age & -0.007 & -0.044 & $-0.023-0.009$ & & & & & & \\
\hline Gender & -0.065 & -0.029 & $-0.282-0.153$ & & & & & & \\
\hline Marital status & -0.098 & -0.077 & $-0.227-0.031$ & & & & & & \\
\hline Secure relations & $0.692^{* * *}$ & 0.662 & $0.590-0.794$ & & & & & & \\
\hline $\begin{array}{l}\text { Sense of control and } \\
\text { knowledge }\end{array}$ & $0.144^{* *}$ & 0.142 & $0.046-0.242$ & & & & & & \\
\hline Perceived health & $0.126^{*}$ & 0.130 & $0.029-0.223$ & & & & & & \\
\hline Security alarm & -0.205 & -0.077 & $-0.467-0.058$ & & & & & & \\
\hline$R$ & \multicolumn{3}{|c|}{$0.730^{1}$} & \multicolumn{3}{|c|}{$0.808^{2}$} & \multicolumn{3}{|c|}{$0.715^{3}$} \\
\hline
\end{tabular}

${ }^{*} p<0.05 ;{ }^{* *} p<0.01 ;{ }^{* * *} p<0.001 ;{ }^{1}$ Model $1 ;{ }^{2}$ Model $2 ;{ }^{3}$ Model 3 .

living in private homes (see Table 2).

\section{DISCUSSION}

In this study, we wanted to describe and analyze factors that may relate to a sense of security for older persons receiving old-age care in Sweden. We also wanted to investigate whether there is a difference between residents in NH and residents that receive care and services in their $\mathrm{PH}$, and to explore factors related to sense of security. Overall, most of the participants felt secure, but the results also demonstrate significant differences in sense of security between persons living in $\mathrm{PH}$ and $\mathrm{NH}$, where those living in NH feel more secure. Secure relationships and perceived health are significantly related to sense of security, as well as having control and knowledge about situations in everyday life. Interestingly, use of a personal security response system was not significantly related to feelings of security in everyday life. Our results can be used to help understand factors that promote security for older persons by increasing knowledge and relationships with the elderly living in $\mathrm{PH}$ and $\mathrm{NH}$, so that the forthcoming political decisions and priorities can be based on the needs of the elderly.

The question is why is there a difference in sense of security between persons living in $\mathrm{PH}$ and $\mathrm{NH}$, where persons in $\mathrm{NH}$ more often expressed feelings of security. We believe that one possible explanation might be that those living in $\mathrm{NH}$ have greater access to staff when in need of care or support than persons living in $\mathrm{PH}$. In Sweden, as in much of the world, the care of the elderly has not kept up with demographic changes in the population [25]. Because the trend is towards aging in place, thereby leaving many older persons lacking access to social care staff, we believe that the older person's sense of security is affected. Research regarding changes in Swedish elderly care show that the care of the elderly has declined for three decades, and more older persons with declining health are living at home. During the 1980s and 1990s, the number of persons living in NH as well as the number of older persons receiving home care has decreased, with more than 30,000 care places [25], meaning that every fourth place in NHs has been removed. Thus, the older persons in our study expressed increased sense of security in $\mathrm{NH}$ as progressively more 
nursing homes are being shut down, which might affect the sense of security. Therefore, we believe that the opportunities for promoting sense of security for those aging in place must be strengthened. For example, the security alarm, which will be discussed later on in this article, has not been shown to provide the sense of security that was previously believed. We believe that there is a need for further research from the older person's perspective of what promotes sense of security while living at home or when moving to a nursing home, and what promotes sense of security during this process.

Secure relationships are of importance for sense of security, and are therefore factors that need to be improved in order to promote sense of security. "Secure relations" strongly correlated to "sense of security", suggesting that care relationships in both PHs and NHs are important for promoting sense of security [26-28]. Correlations between sense of security and relationships were shown by others, but were associated with social networks such as family and friends [4,13,18,29]. It is important to consider that relationships do not necessarily have to do with persons (family, acquaintances, and/ or staff), but could also be related to one's daily routines in everyday life as well as relationships in the home environment [29]. For example, in a recent qualitative study that used story interviews, care receivers expressed that they attained sense of security when the health care personnel had daily routines and "came quite often" [14]. Different aspects of the health/social care staff's responses and treatments in everyday life, including aspects like consideration for every unique situation, respect, letting the older person participate in decisions, and regarding confidence, are due to sense of security. Our results indicate that all these components are of importance for promoting an increased sense of security for the older person. Deficiencies in the staff working in eldercare [30] have been debated when evaluations showed that the staff's improved knowledge did not change their ways of working [31]. The relationship between the older person and the social care worker could, however, also be seen as a challenge, since the older person cannot chose their own staff. The relationship has impact on sense of security, but the older person is, in many ways, dependent on the staff regardless of the quality of the relationship, often due to the decreased independence that comes with age.

What our study also confirmed was correlations between "sense of control and knowledge" and "sense of security", which was initiated by others. For example, having control over service routines as well as having knowledge about the aging process itself seemed to be important for sense of security [32,14]. However, the benefits of control seemed to be attenuated as the physical impairments became more severe [33], which is interes- ting since many older persons in our study were frail, or had co-morbidities and/or cognitive impairments. While aging in place is considered to be the best alternative for the older person [34], health declines due to disability, feelings of insecurity, and risk of falling [35] somehow indicate moving the person to a nursing home. However, older persons do request maintaining control and knowledge over their life span, since declining functional ability and health may not be the only reasons for feelings of insecurity for that person [36], but also a reduction of control and knowledge of one's prevailing situation. We therefore suggest increasing control and knowledge for older persons who are dependent on care from formal political intentions to a personal level, such as deciding what to wear. The category "sense of control and knowledge" in our study included one question about knowing where to turn if they wanted to complain, which could be seen as something natural for older persons receiving care. However, a recent study about complaints from older persons to the municipalities showed that very few complaints are received [37]. The main reason for fewer complaints was considered to be lack of control and knowledge about where and to whom the complaints should be addressed [37]. A concrete example of improvement could therefore be to facilitate clear instructions on the internet regarding, for instance, application forms and findings that affect the elderly, since locating this information on home web pages is sometimes difficult. Every municipality could also provide clearer instructions on where to complain on their homepages for everyday situations, since not everyone has the opportunity or knowledge of how to use a computer to access the internet.

Even though technology is constantly developing in many areas around the world, technology development within the interdisciplinary field of Gerontechnology has not been integrated into municipal eldercare. Personal security alarm systems are one example of this, where our results suggest that use of a security alarm was not related to feeling of security in everyday life for the recipients of care in $\mathrm{PH}$. Found et al. [35] similarly found that despite use of security alarms in $\mathrm{PH}$, older persons did not feel fully secure. In a qualitative study based on focus groups with older persons (aged 67 - 97 years) living in senior housing, security alarms seemed to limit rather than liberate older persons [24]. The security alarms have been used in Sweden since 1974 to reduce feelings of insecurity for older persons [38], but there are reasons to believe that it has not succeeded. Rather, the current system might result in a false sense of security for the older person. We suggest that the security alarm decreases the sense of insecurity regarding accidents or preventing risk of falling [8]. On the other hand, the security alarm limits the person's freedom, since it only 
works within the person's home. In other words, the security alarms decrease the risk of accidents, but simultaneously do not promote a sense of security; therefore, it affects the quality of life in later life and aging well [1-5]. The results of this study also indicated significant relationships between sense of security and perceived health, which is in line with Segesten [15] and the World Health Organization [39]. Perceived health is a resource for achieving wellbeing, and when the person does not experience good health, it results in a direct reduction in one's sense of security [40].

\section{LIMITATIONS}

Apart from the numerous theoretical models of security, there are difficulties that need to be taken into account. Firstly, one has to consider that it is difficult to find a conventional definition of the concept "sense of security" since "security" has different meanings at different times during our lives. Secondly, there are translational difficulties between languages [14], which might make the concept even more difficult to approach. Thirdly, it seems to be common to relate "security" to different risk perspectives [2,3]. Looking into reports, surveys, and research, the focus of security is connected to risk perspectives and health declines rather than what promotes security and health for the older person $[13,18]$.

The methodological limitation of this study is the response rate of $31 \%$, which initially might be considered as a limitation. We believe that there are at least three major arguments for the reliability of this study, despite the seemingly low response rate. Based on the fact that this population often experiences frailty, co-morbidities, and/or cognitive impairments, the response rate of $31 \%$ is not that low. All respondents in this study stated that they had answered the questions themselves, and this selection was necessary in order to reach the aim of this study. Other evaluations concerning older persons' own experience of the care they are receiving (user perspective) have been criticized owing to the responses that were provided by relatives or health care staff [5]. We wanted to avoid this criticism and therefore excluded all persons who stated that they did not answer the questionnaire themselves. It must also be noted that the analyses were conducted as secondary analyses, implying that the authors did not influence the questions included in the survey.

\section{CONCLUSIONS}

Sense of security is important for aging well throughout the life span, but little is still known about how to promote the sense of security to older persons when they are dependent and in need of health and social care. This study indicates that sense of security among older persons that use health and social care, in private homes and in nursing homes, differs depending on what context and health condition the old person is in. Older persons living in nursing homes feel more secure compared to old persons in private homes and personal emergency response alarm has no significant relationships to the sense of security. Furthermore, relationships, sense of control, and perceived health are significantly related to the sense of security in both private homes and nursing homes. In conclusion, the health and social care organizations need to strengthen the control, knowledge and relationships in order to promote the sense of security for persons in old age.

\section{REFERENCES}

[1] Torstensson Levander, M. (2007) Trygghet, säkerhet, oro eller risk? (Security, safety, concern or risk?). Stockholm.

[2] Hale, C. (1996) Fear of crime: A review of the literature. International Journal of Victmology, 4, 79-150.

[3] De Donder, L. (2012) Individual risk factors of feelings of unsafety in later life. European Journal of Ageing, 9, 233.

[4] De Donder, L. (2012) Social capital and feelings of unsafety in later life: A study on the influence of social networks, place attachment and civic participation on perceived safety in Belgium. Resarch on Ageing, 34, 425448. doi:10.1177/0164027511433879

[5] Lindgren, L. (2011) How are the user surveys used? An overview of research and perspectives on surveys (Huranvändsbrukarundersökningar? En översikt av forskningen och perspektiv på kunskapsöversikter). FoU Väst, Rapport 3.

[6] National Board of Health and Welfare (2011) Lägesrapport.

[7] Wånell, E. (2004) Growing old together-A book about aging and elderly care (Bo på äldre da'r. Att åldras tillsammans-En bok om åldrandet och äldreomsorgen). Äldrecentrum/PRO, Stockholm.

[8] Fonad, E. (2008) Older people's safety and security in community care for the elderly: Focusing on fall risk and fall. Dissertation Thesis, Karolinska Institutet, Stockholm.

[9] Yen, I. and Anderson, L. (2012) Built environment and mobility of older adults: Important policy and practice efforts. Journal of the American Geriatrics Society, 60, 951-956. doi:10.1111/j.1532-5415.2012.03949.x

[10] Mastrian, K.G. (2001) Differing perceptions in defining safe independent living for elders. Nursing Outlook, 49, 231-237. doi:10.1067/mno.2001.115491

[11] Social Service Law (2001) Chapter 1 mission statement. Socialtjänstlagen, 453.

[12] Wikström, E. (2005) The paradox of influence (Inflytandets paradoxer). Linneuniversitetet, Växjö.

[13] Fagerström, L., Gustafson, Y., Jakobsson, G., Johansson, S. and Vartiainen, P. (2011) Sense of security among peo- 
ple aged 65 and 75. External and inner sources of security. Journal of Advanced Nursing, 67, 1305-1316. doi:10.1111/j.1365-2648.2010.05562.x

[14] Petersson, P. and Blomqvist, K. (2011) Sense of security - Search in for its meaning by using stories: A particatory action research study in health and social care in Sweden. International journal of Older People Nursing, 6, 25-32. doi:10.1111/j.1748-3743.2010.00211.x

[15] Segesten, K. (1984) Patienters upplevesler av trygghet och otrygghet. In: Förlag, S., Ed., Omvårdnad och Trygghet-En Metateoretisk och Fenomenologisk Studie. Göteborgs Universitet, Göteborg.

[16] Andersson-Segesten, K. (1991) Patient's experience of uncertainty in illness in two intensive coronary care units. Scandinavian Journal of Caring Sceiences, 5, 543-548

[17] Giddens, A. (1989) Anthony Giddens and social sciences (Anthony giddens och samhällsvetenskapen). Stockholm.

[18] Carro, D., Valera, S. and Vidal, T. (2010) Perceived insecurity in teh public space: Personal, social and enviromental variables. Qualitative and Quantiative, 44, 303314. doi:10.1007/s11135-008-9200-0

[19] Sörman, H. (2010) Open comparisons 2010 Residential care for the elderly (Öppna jämförelser 2010 Vård och omsorg om äldre).

[20] National Board of Health and Welfare (2011) Methodological Appendix Open comparisons regarding older persons (Socialstyrelsens Metodbilaga Öppna jämförelser Äldreguiden).

[21] Acierno, R., Rheingold, A., Resnick, H. and Kilpatrick, D. (2004) Predictors of fear of crime in older adults. Anxiety Disorders, 18, 385-396. doi:10.1016/S0887-6185(03)00012-4

[22] Stiles, B., Halim, S. and Kaplan, H. (2003) Fear of crime among individuals with physical limitations. Criminal Justice Review, 28, 232-253. doi:10.1177/073401680302800203

[23] Killias, M. and Clerici, C. (2002) Different measures of vulnerability in their relations to different dimensions of fear of crime. British Journal of Criminology, 40, 437450. doi:10.1093/bjc/40.3.437

[24] Boström, M., Kjellström, S., Malmberg, B. and Björklund, A. (2011) Personal emergency response system (PERS) alarms may induce insecurity feelings. Gerontechnology, 11, 136-141.

[25] Szebehely, M. and Ulmanen, P. (2012) Price of the scueeze in old age care, how does this affect the middleage children? (Åtstramningens pris, Hur påverkas de medelålders barnen av äldreomsorgens minskning?). Institutionen för Socialt Arbete, Stockholm.

[26] Johns, J. (1996) A concept analysis of trust. Journal of Advanced Nursing, 24, 76-83. doi:10.1046/j.1365-2648.1996.16310.x

[27] Mok, E. (2004) Nurse-patient relationchop in palliative care. Journal of Advanced Nursing, 48, 475-483. doi:10.1111/j.1365-2648.2004.03230.x

[28] Tarlier, D. (2004) Beyond caring: The moral and ethical bases of responsive nurse-patient relationships. Nursing Philosophy, 5, 230-241.

doi:10.1111/j.1466-769X.2004.00182.x

[29] Dupuis, A. and Thorns, D. (2002) Home, home ownership and the search for ontological security. The Sociological Review, 46, 24-47. doi:10.1111/1467-954X.00088

[30] Ministry of Social Affairs (2007) Close learning. Support to municipalities for skills and training in the care of the elderly (Socialdepartementet Att lära nära Stöd till kommuner för verksamhetsnära kompetensutveckling inom omsorg och vård av äldre).

[31] Westerberg, B. and Sundell, K. (2009) Staff training in the elderly-Will it be benefiting the elderly? An evaluation of the competence ladder, the institute for the development of methods in social work, IMS, The National Board of Health and Welfare (Personalutbildning $i$ äldreomsorg — Blir den till nytta för de äldre? En utvärdering av Kompetensstegen). Institutet för Utveckling av Metoder i Socialt Arbetet IMS, Socialstyrelsen, 126-179.

[32] Nuevo, R., Loebach, W.M., Montorio, I., Ruiz, M. and Cabrea, I. (2009) Knowledge about aging and worry in older adults: Testing the mediation role of intolerance of uncertainty. Aging \& Mental Health, 33, 135-141. doi:10.1080/13607860802591088

[33] Clarke, P. and Smith, J. (2011) Aging in a cultural context: Cross-national differences in disability and the moderating role of personal control among older adults in the United States and England. Journals of Gerontology Series B: Psychological Sciences \& Social Sciences, 66B, 457-467. doi:10.1093/geronb/gbr054

[34] Kulla, G., Sarvaimäki, A. and Fagerström, L. (2006) Health resources and health strategies among older Swedish-speaking Finns-A hermeneutic study. Scandinavian Journal of Caring Sciences, 20, 51-57. doi:10.1111/j.1471-6712.2006.00379.x

[35] Fonad, E., Wahlin, T., Heikkilä, K. and Emami, A. (2008) Moving to and living in a retirement home: Focusing on elderly people's sense of safety and security. Journal of Housing of the Elderly, 20, 45-60. doi:10.1300/J081v20n03 04

[36] Retirement homes Delegation (2008) Bor bra hela livet fritze. Stockholm.

[37] Harnett, T. (2010) The trivial matters Everyday power in Swedish elder care. Dissertation Thesis, School of Health Sciences, Jönköping.

[38] Östlund Gammal är äldst (1995) Old people are the most experienced. A Study of the meaning of technology in old people's every day life (En studie av teknik i äldre människors liv). Linköpings University, Linköpings.

[39] World Health Organization (2004) A glossary of terms for community health care and services for older persons. World Health Organization, Geneva.

[40] Tamm, M. (1991) Psychological theories in caring (Psykologiska teorier i vården). Akademiförlaget, Göteborg. 